\title{
Model Electrode Studies of the Electrostatic Interaction between Electrochemically Dissolved Pt Ions and $\mathrm{RuO}_{2}$ Nanosheets
}

\author{
Qingfeng Liu, Koodlur S. Lokesh, ${ }^{a}$ Christophe Chauvin," and Wataru Sugimoto*,z \\ Materials and Chemical Engineering, Faculty of Textile Science and Technology, Shinshu University, Ueda, \\ Nagano 386-8567, Japan
}

\begin{abstract}
Model electrodes consisting of ruthenium oxide nanosheets coated on freshly cleaved highly oriented pyrolytic graphite $\left(\mathrm{RuO}_{2}\right.$ nanosheet/HOPG) were prepared to investigate the electrostatic interactions between $\mathrm{RuO}_{2}$ nanosheets and electrochemically dissolved Pt ions. The $\mathrm{RuO}_{2}$ nanosheet/HOPG model electrode was dipped into a solution containing dissolved Pt ions generated by potential cycling a Pt working electrode in sulfuric acid electrolyte. Scanning tunneling microscopy revealed preferential adsorption of Pt ions on the nanosheets as island-like deposits, while no such deposits were observed on HOPG. This shows the strong electrostatic interactions between the positively-charged Pt ions and negatively-charged nanosheet. The calculated amount of Pt ions adsorbed was $0.93 \times 10^{6}$ atoms $\mu \mathrm{m}^{-2}$, which agreed with the theoretical saturated adsorption amount of $\mathrm{Pt}_{\text {ion }}$ on $\mathrm{RuO}_{2}$ nanosheet of $0.96 \times 10^{6}$ atoms $\mu \mathrm{m}^{-2}$. All of the Pt ions could be electrochemically reduced to Pt nanoparticles showing activity toward the oxygen reduction reaction.

(C) 2013 The Electrochemical Society. [DOI: 10.1149/2.050403jes] All rights reserved.
\end{abstract}

Manuscript submitted October 17, 2013; revised manuscript received December 17, 2013. Published December 28, 2013.

Platinum supported on carbon $(\mathrm{Pt} / \mathrm{C})$ is widely used as a cathode catalyst in polymer electrolyte fuel cells because of its high oxygen reduction reaction (ORR) activity. The loss of electrocatalytic activity during fuel cell operation is a detrimental factor to the useful lifetime of commercial polymer electrolyte fuel cell systems. Hence, there is a strong demand to improve the durability of electrocatalyst to realize the wide-spread commercialization of polymer electrolyte fuel cells. Numerous studies have clarified that dissolution, migration and/or sintering of platinum nanoparticles on carbon are vital degradation factors of the cathode catalyst. ${ }^{1-3}$ Oxides that are stable under acidic and oxidizing conditions have been suggested to enhance the durability of $\mathrm{Pt}$ as cathode catalysts. For example, $\mathrm{SnO}_{2}$ has been proposed as an alternative support to replace carbon to enhance the durability of $\mathrm{Pt}$ catalyst due to its resistance to corrosion. ${ }^{4} \mathrm{TiO}_{2}$ added to $\mathrm{Pt} / \mathrm{C}$ was suggested to anchor platinum particles, preventing agglomeration and coalescence during durability testing. ${ }^{5,6}$ Carbon supported Pt covered with a thin layer of $\mathrm{SiO}_{2}$ has been shown to exhibit high stability during potential cycling in $\mathrm{H}_{2} \mathrm{SO}_{4}$ electrolyte. ${ }^{7,8}$ The foundation of the increase in durability due to the addition of these oxides is not well understood. In addition, due to the poor conductivity of these oxides, the original properties of $\mathrm{Pt} / \mathrm{C}$ are often inevitably obstructed, which includes the loss of initial electrochemical surface area (ECSA) and ORR activity with the addition of oxides.

Contrary to most other oxide systems, $\mathrm{RuO}_{2}$ nanostructures possess excellent electronic conductivity and electrochemical stability, making them an ideal additive that would not obstruct electrode kinetics. Indeed, we and others have found that the combination of $\mathrm{RuO}_{2}$ nanostructures and $\mathrm{Pt}$ nanoparticles can enhance ORR properties. For example, incorporation of carbon-supported $\mathrm{RuO}_{2}\left(\mathrm{RuO}_{2} / \mathrm{C}\right)$ to Pt was found to ameliorate both stability and activity of the cathode catalyst. ${ }^{9}$ We have reported that the ORR activity and durability of commercial $\mathrm{Pt} / \mathrm{C}$ are improved by the modification with $\mathrm{RuO}_{2}$ nanosheets. ${ }^{10-12}$ Because of the complex structure of the porous carbon support in commercial catalyst coupled with the ultimate thickness of the nanosheet of $1 \mathrm{~nm}$, it was difficult to obtain conclusive evidence to explain the mechanism of the improvement on the catalyst durability. Therefore, studies of a simple model electrode system are desired to understand the enhanced durability of $\mathrm{Pt} / \mathrm{C}$ electrocatalyst modified with $\mathrm{RuO}_{2}$ nanosheets. The requirement for an ideal model electrode is that the electrode should be accessible to certain analytical techniques before, during and after the involved catalytic process. Model electrodes are generally prepared by

*Electrochemical Society Active Member.

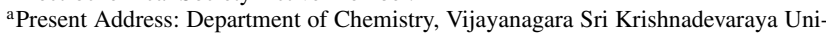
versity, Bellary, Karnataka 583105, India.

zE-mail: wsugi@shinshu-u.ac.jp depositing platinum nanoparticles on two-dimensional, planar carbon substrate such as glassy carbon (GC) or highly orientated pyrolytic graphite (HOPG) by electrodeposition, ${ }^{13-17}$ vapor deposition ${ }^{18}$ or lithography. ${ }^{19,20}$ Surface analysis methods, such as scanning tunneling microscopy (STM), atomic force microscopy (AFM), scanning electron microscopy (SEM) are often used to characterize the electrochemical process of model electrodes. ${ }^{13-20}$

In this work, model electrode studies with HOPG substrate were performed to investigate the interaction between $\mathrm{RuO}_{2}$ nanosheets and dissolved Pt ions which were generated electrochemically in an attempt to clarify the enhanced durability of Pt/C electrocatalyst modified with the nanosheets. STM and AFM were utilized to observe the adsorption and reduction behavior of dissolved $\mathrm{Pt}$ ions on the $\mathrm{RuO}_{2}$ nanosheet/HOPG model electrode.

\section{Experimental}

Ruthenium oxide nanosheets were synthesized by elemental exfoliation of an ion-exchangeable layered potassium ruthenate $\left(\mathrm{K}_{0.2} \mathrm{RuO}_{2.1} \cdot n \mathrm{H}_{2} \mathrm{O}\right){ }^{21,22}$ Proton-exchange of the interlayer potassium was conducted with $1 \mathrm{~mol} \mathrm{dm}{ }^{-3} \mathrm{HCl}$ for 3 days at $60^{\circ} \mathrm{C}$, resulting in the layered ruthenic acid $\left(\mathrm{H}_{0.2} \mathrm{RuO}_{2.1} \cdot 0.9 \mathrm{H}_{2} \mathrm{O}\right)$. The layered ruthenic acid was added to a tetrabutylammonium hydroxide (TBAOH) aqueous solution with the molar ratio of TBA ions to the exchangeable protons in $\mathrm{H}_{0.2} \mathrm{RuO}_{2.1} \cdot n \mathrm{H}_{2} \mathrm{O}$ adjusted to $\mathrm{TBA}^{+} / \mathrm{H}^{+}=1.5$. The dispersion was vigorously shaken for 10 days to exfoliate the layered ruthenate into elementary $\mathrm{RuO}_{2}$ nanosheets. Non-exfoliated impurity was removed by centrifugation at $2000 \mathrm{rpm}$ for $30 \mathrm{~min}$. The asexfoliated nanosheet colloid was finally diluted to $0.1\left(\mathrm{~g}-\mathrm{RuO}_{2}\right) \mathrm{L}^{-1}$ with ultrapure water (Milli-Q, > $18 \mathrm{M} \Omega \mathrm{cm}$ ). HOPG (Bruker, ZYHgrade, $12 \times 12 \mathrm{~mm}^{2}$ ) was freshly cleaved using adhesive tape and then immersed into the nanosheet colloid for 2 minutes to coat $\mathrm{RuO}_{2}$ nanosheets. The nanosheets coated HOPG $\left(\mathrm{RuO}_{2}\right.$ nanosheet/HOPG) was rinsed with ultrapure water and then dried under vacuum.

Dissolved Pt ions were generated electrochemically by potential cycling a Pt mesh working electrode 500 times between 0.05 to $1.4 \mathrm{~V}$ at a scan rate of $100 \mathrm{mV} \mathrm{s}^{-1}$ in a three-electrode electrochemical cell in $\mathrm{O}_{2}$ saturated $0.5 \mathrm{M} \mathrm{H}_{2} \mathrm{SO}_{4}\left(60^{\circ} \mathrm{C}\right)$. $\mathrm{RuO}_{2}$ nanosheet/HOPG was immersed in this solution for 10 minutes at room temperature to adsorb the dissolved Pt ions.

STM measurements were performed using a scanning tunneling microscope (STM, Bruker, Digital Instruments Nanoscope III D ADC 5) equipped with a $10 \mu \mathrm{m}$ scanner (HD-8I, 2399DI) with the set point current of $1 \mathrm{nA}$. In order to avoid the disturbance of Faraday current on tunneling current, the tip of the PtIr probe (Bruker, Pt-ECM10, $14 \mathrm{~mm}$ length) was partially coated by nail polish as an insulating layer. The geometric area of the working electrode (WE) in contact with the 
electrolyte was $0.5 \mathrm{~cm}^{2}$. Images were recorded using $\mathrm{SiN}$ probe (Bruker, SNL-10). The test sample acted as the working electrode and two high purity $\mathrm{Pt}$ wires with a diameter of $0.1 \mathrm{~mm}$ acted as the reference electrode (RE) and the counter electrode (CE). An electrochemical-atomic force microscope (EC-AFM, Bruker, Digital Instruments Nanoscope III D ADC 5) equipped with a bi-potentiostat was used. Electrochemical reduction of adsorbed Pt ions was conducted by slow-scan linear sweep voltammetry from 1.1 to $0 \mathrm{~V}$ (cathodic scan) at $0.25 \mathrm{mV} \mathrm{s}^{-1}$. The time for the image acquisition was approximately 5 minutes. Both STM and AFM images were processed using Nanoscope V531r1 software.

The ORR activity of reduced $\mathrm{Pt}$ ions adsorbed on $\mathrm{RuO}_{2}$ nanosheets was investigated in a standard three-electrode electrochemical cell with $0.5 \mathrm{M} \mathrm{H}_{2} \mathrm{SO}_{4}$ as electrolyte. Carbon fiber (Toho, Tenax-J, HTS40 E13) was used as the counter electrode and a reversible hydrogen electrode (RHE) was used as the reference electrode. Electrochemical reduction was conducted by slow-scan linear sweep voltammetry from 1.1 to $0 \mathrm{~V}$ (cathodic scan) at $0.25 \mathrm{mV} \mathrm{s}^{-1}$. Linear sweep voltammetry (LSV) was then conducted at $10 \mathrm{mV} \mathrm{s}^{-1}$ from 0.05 to $1.2 \mathrm{~V}$ vs. RHE in $\mathrm{O}_{2}$-saturated $0.5 \mathrm{M} \mathrm{H}_{2} \mathrm{SO}_{4}\left(25^{\circ} \mathrm{C}\right)$. The $\mathrm{LSV}$ data collected in $\mathrm{N}_{2}$ purged electrolyte was used as background and subtracted from the data recorded in $\mathrm{O}_{2}$-saturated $0.5 \mathrm{M} \mathrm{H}_{2} \mathrm{SO}_{4}$.

\section{Results and Discussion}

A typical STM image of $\mathrm{RuO}_{2}$ nanosheets supported on HOPG observed in $0.5 \mathrm{M} \mathrm{H}_{2} \mathrm{SO}_{4}$ is shown in Figure 1. The height profiles of a number of specimens showed that the nanosheets have a thickness of 1 $\pm 0.1 \mathrm{~nm}$ with several hundreds of nanometers in lateral size, revealing complete exfoliation into monolayer. Respective STM images in air
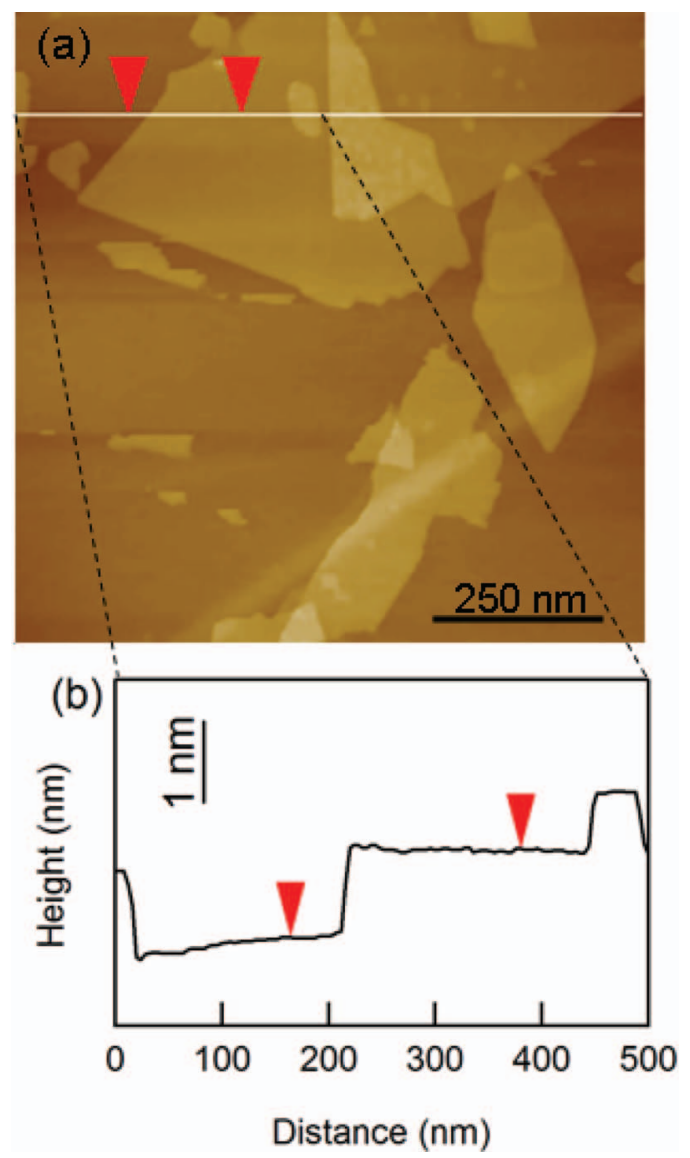

Figure 1. Typical STM image of $\mathrm{RuO}_{2}$ nanosheets supported on HOPG in $0.5 \mathrm{M} \mathrm{H}_{2} \mathrm{SO}_{4}$. (a) topographic image and (b) height profile. The $z$-range is $20 \mathrm{~nm}$.

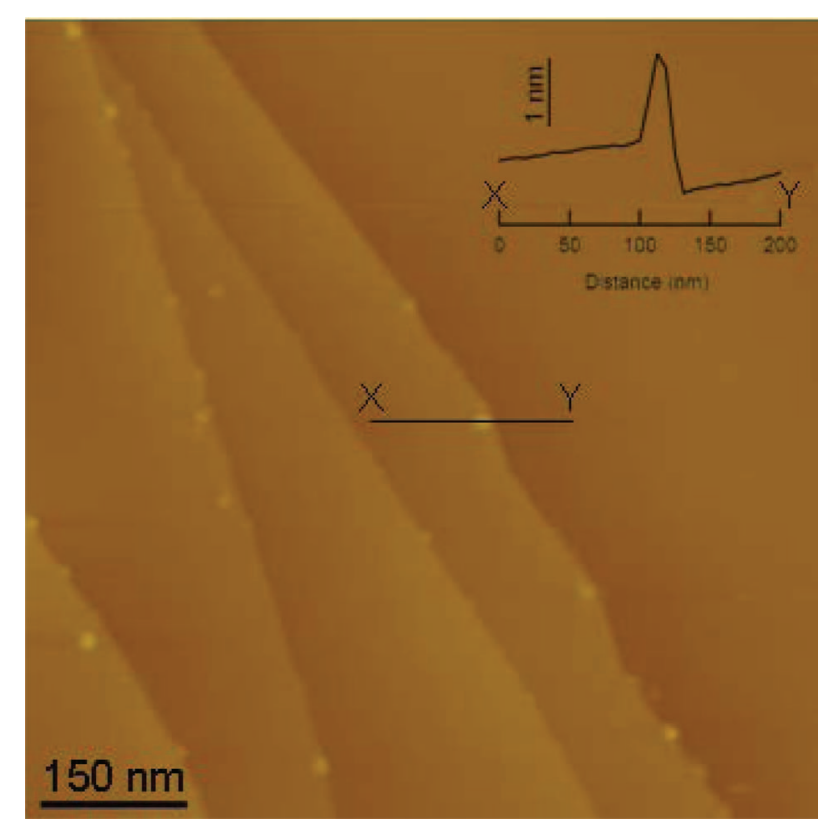

Figure 2. AFM image of as-cleaved HOPG surface after immersed in $0.5 \mathrm{M}$ $\mathrm{H}_{2} \mathrm{SO}_{4}$ containing $\mathrm{Pt}$ ions. The $z$-range is $20 \mathrm{~nm}$.

were also collected and were in good agreement to our previous AFM data. ${ }^{22,23}$ The thickness of the $\mathrm{RuO}_{2}$ nanosheets both in air and in $0.5 \mathrm{M} \mathrm{H}_{2} \mathrm{SO}_{4}$ were the same. This indicates that the $\mathrm{RuO}_{2}$ nanosheets are fairly well fixed on the HOPG substrate and does not drift away from the substrate in aqueous solution. This allows to investigate the adsorption of dissolved $\mathrm{Pt}$ ions on the surface of $\mathrm{RuO}_{2}$ nanosheets using STM or AFM.

Spontaneous formation of Pt nanoparticles on as-cleaved HOPG surface in chloride electrolytes containing $\mathrm{PtCl}_{6}{ }^{2-}$ is known to occur. $^{13,24}$ The driving force for this process has been suggested to be related to the presence of incompletely oxidized functionalities existing at terraces and kink sites on freshly cleaved HOPG surface. ${ }^{13}$ Here, we immersed an as-cleaved HOPG into $0.5 \mathrm{M} \mathrm{H}_{2} \mathrm{SO}_{4}$ containing electrochemically dissolved $\mathrm{Pt}$ ions to evaluate the chemical interaction between dissolved Pt ions and HOPG. As seen in Figure 2, individual Pt nanoparticles can be observed at the edge sites on the HOPG surface, which indicates that dissolved Pt ions have properties similar to $\mathrm{PtCl}_{6}{ }^{2-}$. The individual $\mathrm{Pt}$ nanoparticles have an average diameter of $10-20 \mathrm{~nm}$ with height of about $1.5-2.5 \mathrm{~nm}$, similar in geometry to $\mathrm{Pt}$ nanoparticles reduced on the edge sites of HOPG from $\mathrm{PtCl}_{6}{ }^{2-} \cdot{ }^{13,24}$ It is assumed that the dissolved $\mathrm{Pt}$ ions are spontaneously reduced by the incompletely oxidized functionalities at the edge sites, analogous to the case for $\mathrm{PtCl}_{6}{ }^{2-} \cdot{ }^{13}$ The characteristic plate-like morphology may come from the high mobility of as-reduced Pt on the HOPG surface leading to a two-dimensional growth.

In order to investigate the interaction between $\mathrm{RuO}_{2}$ nanosheets and dissolved $\mathrm{Pt}$ ions, the $\mathrm{RuO}_{2}$ nanosheet/HOPG was immersed into $0.5 \mathrm{M} \mathrm{H}_{2} \mathrm{SO}_{4}$ containing dissolved $\mathrm{Pt}$ ions, dried, and characterized by STM. Figure 3a shows a 3D topographic STM image of $\mathrm{RuO}_{2}$ nanosheet/HOPG after adsorption of dissolved Pt ions, showing island-like deposits on the surface of nanosheets. Figure $3 \mathrm{~b}$ shows the top-view STM image corresponding to Figure 3a. The deposits are aligned parallel to each other, possibly reflecting the atomic arrangement of the the nanosheet surface. Note that no deposits appear on the surface of HOPG. The height profile (Figure 3c) shows that the island-like deposits are several tens of nanometers in diameter and $\sim 1.8 \mathrm{~nm}$ in height.

Dissolved Pt ions in sulfuric acid have been detected as cationic $\mathrm{Pt}^{2+}$ and $\mathrm{Pt}^{4+}$ species. ${ }^{25}$ The solvation shell of hydrated $\mathrm{Pt}$ ion was 

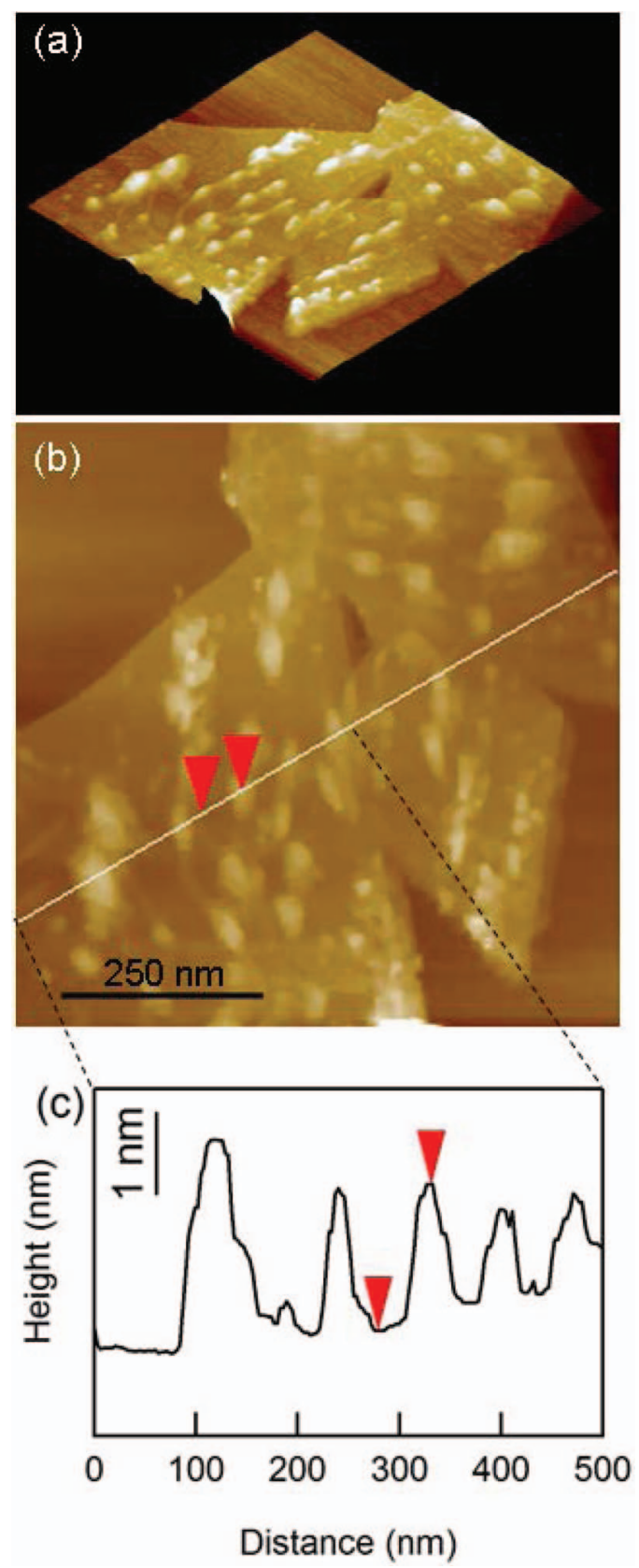

Figure 3. (a) 3D topographic STM image, (b) top-view image, and (c) height profile of dissolved $\mathrm{Pt}$ ions adsorbed on $\mathrm{RuO}_{2}$ nanosheets in $0.5 \mathrm{M} \mathrm{H}_{2} \mathrm{SO}_{4}$ The $z$-range is $20 \mathrm{~nm}$.

calculated as eight water molecules, making the diameter of the hydrated Pt ion to be approximately $0.79 \mathrm{~nm}^{26}$ A dense monolayer of hydrated $\mathrm{Pt}$ ion should then give a coverage of $1.85 \times 10^{6} \mathrm{Pt}^{n+} \mu \mathrm{m}^{-2}$. As the average height of the island-like deposits is $\sim 1.8 \mathrm{~nm}$ (Figure 3), the deposits should be formed by 2 or 3 layers of hydrated Pt ion. The coverage of the deposits was $22 \%$, which translates to a coverage of $50 \%$ for a monolayer adsorption. The amount of hydrated $\mathrm{Pt}$ ion on the surface of nanosheet is thus calculated to be $0.93 \times 10^{6} \mathrm{Pt}^{n+} \mu \mathrm{m}^{-2}$.

Next, we consider the amount of $\mathrm{Pt}^{n+}$ adsorption theoretically possible based on the surface charge of $\mathrm{RuO}_{2}$ nanosheet. Assuming that the crystal structure of $\mathrm{RuO}_{2}$ nanosheet is close to rutile-type $\mathrm{RuO}_{2}$ (density of $6.97 \mathrm{~g} \mathrm{~cm}^{-3}$ ), the amount of Ru atoms in a $1 \mathrm{~nm}$ thick sheet is calculated as $3.07 \times 10^{7}$ atoms $\mu \mathrm{m}^{-2}$. $\mathrm{RuO}_{2}$ nanosheet has a formal composition of $\left(\mathrm{RuO}_{2.1}\right)^{0.2-}, 23$ which means that the number

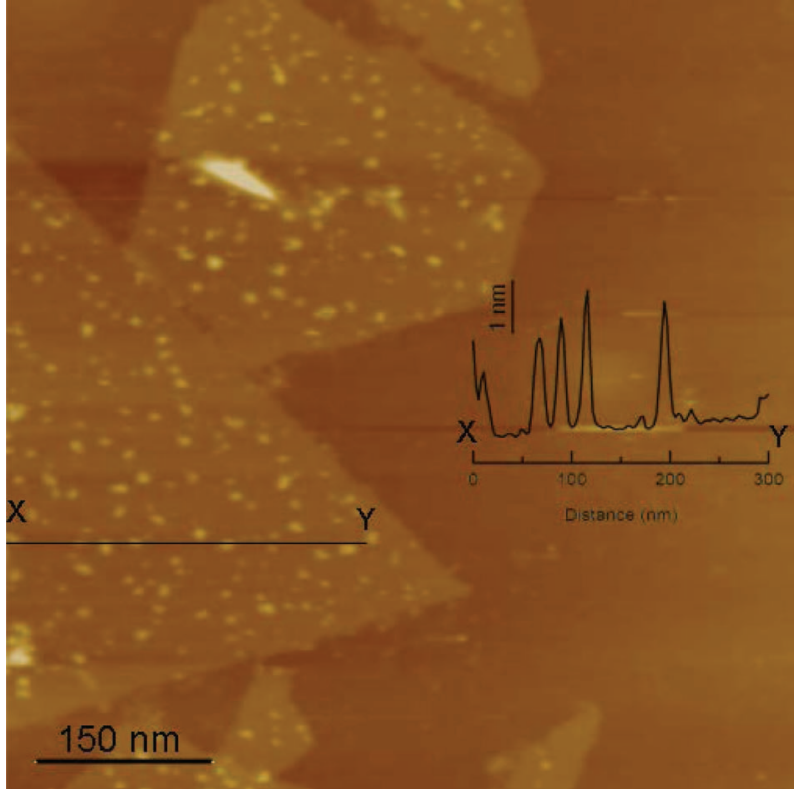

Figure 4. AFM image after electrochemical reduction of dissolved Pt ions adsorbed on $\mathrm{RuO}_{2}$ nanosheets. The $z$-range is $20 \mathrm{~nm}$.

of negative charge will be $6.14 \times 10^{6}$ sites $\mu \mathrm{m}^{-2}$. Considering that only one side of nanosheet is exposed to the electrolyte, the actual number of negative charge should be half, thus giving $3.07 \times 10^{6}$ sites $\mu \mathrm{m}^{-2}$. Then, the saturated adsorption amount for $\mathrm{Pt}^{2+}$ and $\mathrm{Pt}^{4+}$ should be $1.54 \times 10^{6}$ and $0.77 \times 10^{6}$ atoms $\mu \mathrm{m}^{-2}$, respectively. Since the ratio of $\mathrm{Pt}^{2+}$ to $\mathrm{Pt}^{4+}$ has been detected as approximately $1: 3 \mathrm{in}_{2} \mathrm{SO}_{4},{ }^{25}$ the final amount of adsorbed Pt ions should be 0.96 $\times 10^{6}$ atoms $\mu \mathrm{m}^{-2}$. Thus, the amount of hydrated $\mathrm{Pt}$ ion adsorbed on nanosheet estimated from the STM images (Figure 3) shows a close match to the estimated saturated adsorption amount of cationic $\mathrm{Pt}$ ions on $\mathrm{RuO}_{2}$ nanosheet surface. This undoubtedly implies that the adsorption of $\mathrm{Pt}^{n+}$ on the surface of $\mathrm{RuO}_{2}$ nanosheet is due to the strong electrostatic interactions between hydrated Pt cations and negatively charged $\mathrm{RuO}_{2}$ nanosheets.

The adsorbed Pt ions on $\mathrm{RuO}_{2}$ nanosheet were then electrochemically reduced by performing a cathodic scan from 1.1 to $0 \mathrm{~V}$ at a slow scan rate of $0.25 \mathrm{mV} \mathrm{s}^{-1}$. Figure 4 shows the tapping-mode AFM image after electrochemical reduction. Pt nanoparticles with average height of $2.0 \pm 0.7 \mathrm{~nm}$ and width/length ranging from 2 to $20 \mathrm{~nm}$ were observed on the surface of $\mathrm{RuO}_{2}$ nanosheet. The ORR activity of the Pt nanoparticles decorated on $\mathrm{RuO}_{2}$ nanosheets was investigated in a standard three-electrode electrochemical cell. Figure 5 shows the linear sweep voltammogram of $\mathrm{RuO}_{2}$ nanosheet/HOPG with adsorbed Pt ions after electrochemical reduction. It is clear that Pt nanoparticles supported on the nanosheet show ORR activity. We consider that the ORR activity shown by the reduced Pt nanoparticles on nanosheet contributes to the higher ORR activity retention rate in practical catalyst. As discussed in our previous papers, ${ }^{10-12} \mathrm{RuO}_{2}$ nanosheet modified $\mathrm{Pt} / \mathrm{C}$ electrocatalyst shows enhanced durability compared to non-modified $\mathrm{Pt} / \mathrm{C}$. Certainly, the degradation rate of carbon blacks used in practical catalysts and HOPG used in this model electrode study should be quite different due to the difference in degree of graphitization. Nonetheless, this model electrode study reveals that there is a strong electrostatic interaction between the additive $\mathrm{RuO}_{2}$ nanosheets and dissolved Pt ions. This model electrode study clarifies that the enhancement in durability by addition of $\mathrm{RuO}_{2}$ nanosheet to practical $\mathrm{Pt} / \mathrm{C}$ catalyst can be attributed, at least in part, to the negatively charged $\mathrm{RuO}_{2}$ nanosheets acting as trapping sites to mitigate the migration of adsorbed Pt ions into the electrolyte. 


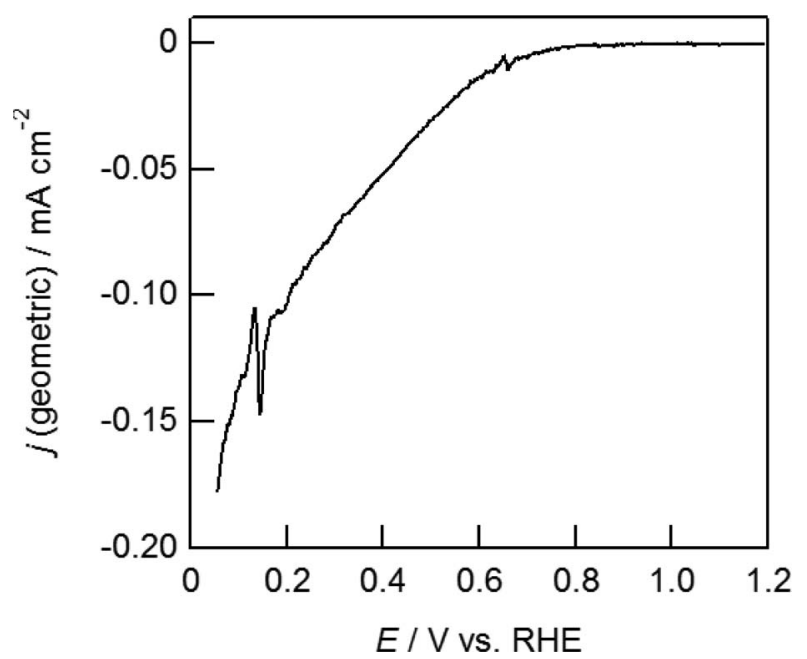

Figure 5. LSV of $\mathrm{RuO}_{2}$ nanosheet/HOPG with adsorbed Pt ions after electrochemical reduction (from 0.05 to $1.2 \mathrm{~V}$ vs. RHE, $10 \mathrm{mV} \mathrm{s}^{-1}, 25^{\circ} \mathrm{C}$ ).

\section{Conclusions}

A $\mathrm{RuO}_{2}$ nanosheet/HOPG model electrode was prepared by dipcoating HOPG into an aqueous solution of $\mathrm{RuO}_{2}$ nanosheet. The adsorption of electrochemically generated dissolved Pt ions in sulfuric acid on $\mathrm{RuO}_{2}$ nanosheet/HOPG was detected by STM. Based on the geometries of the deposits, the amount of hydrated Pt ion on the surface of nanosheets was estimated to be $0.93 \times 10^{6} \mathrm{Pt}^{n+} \mu \mathrm{m}^{-2}$. This value closely matched the full saturated adsorption of Pt ions of $0.96 \times 10^{6} \mathrm{Pt}^{n+} \mu \mathrm{m}^{-2}$ estimated based on the negative charge of the nanosheets. Thus we conclude that the driving force for adsorption of $\mathrm{Pt}$ ions on $\mathrm{RuO}_{2}$ nanosheets is the strong electrostatic interaction between positively charged $\mathrm{Pt}$ ions and negatively charged $\mathrm{RuO}_{2}$ nanosheets. The adsorbed Pt ions could easily be reduced to $\mathrm{Pt}$ nanoparticles by electrochemical reduction, which exhibited ORR activity. The electrostatic interaction between Pt ions and $\mathrm{RuO}_{2}$ nanosheets should facilitate trapping and re-deposition of the Pt ions on $\mathrm{RuO}_{2}$ nanosheets, thereby impede loss of Pt during potential cycling in practical supported catalysts.

\section{Acknowledgments}

This work was supported in part by the "Polymer Electrolyte Fuel Cell Program" from the New Energy and Industrial Technology De- velopment Organization (NEDO) and Grants for Excellent Graduate Schools, MEXT, Japan.

\section{References}

1. P. J. Ferreira, G. J. la O', Y. Shao-Horn, D. Morgan, R. Makharia, S. Kocha, and H. A. Gasteiger, J. Electrochem. Soc., 152, A2256 (2005).

2. Y. Shao, G. Yin, and Y. Gao, J. Power Sources, 171, 558 (2007).

3. M. S. Wilson, F. H. Garzon, K. E. Sickafus, and S. Gottesfeld, J. Electrochem. Soc., 140, 2872 (1993).

4. A. Masao, S. Noda, F. Takasaki, K. Ito, and K. Sasaki, Electrochem. Solid-State Lett., 12, B119 (2009).

5. J. Tian, G. Sun, M. Cai, Q. Mao, and Q. Xin, J. Electrochem. Soc., 155, B187 (2008).

6. X. Liu, J. Chen, G. Liu, L. Zhang, H. Zhang, and B. Yi, J. Power Sources, 195, 4098 (2010).

7. S. Takenaka, H. Matsumori, H. Matsune, E. Tanabe, and M. Kishida, J. Electrochem. Soc., 155, B929 (2008)

8. S. Takenaka, H. Matsumori, H. Matsune, and M. Kishida, Appl. Catal., A, 409-410, 248 (2011).

9. S. V. Selvaganesh, G. Selvarani, P. Sridhar, S. Pitchumani, and A. K. Shukla, J. Electrochem. Soc., 159, B463 (2012).

10. C. Chauvin, Q. Liu, T. Saida, K. S. Lokesh, T. Sakai, and W. Sugimoto, ECS Trans., 50(2), 1583 (2013)

11. D. Takimoto, C. Chauvin, and W. Sugimoto, Electrochem. Commun., 33, 123 (2013).

12. C. Chauvin, T. Saida, and W. Sugimoto, J. Electrochem. Soc., submitted.

13. J. V. Zoval, J. Lee, S. Gorer, and R. M. Penner, J. Phys. Chem. B, 102, 1166 (1998).

14. F. Gloaguen, J. M. Léger, C. Lamy, A. Marmann, U. Stimming, and R. Vogel, Electrochim. Acta, 44, 1805 (1999).

15. G. Lu and G. Zangari, Electrochim. Acta, 51, 2531 (2006)

16. Z. Siroma, K. Ishii, K. Yasuda, M. Inaba, and A. Tasaka, J. Power Sources, 171, 524 (2007).

17. T. Brülle and U. Stimming, J. Electroanal. Chem., 636, 10 (2009).

18. Y. Takasu, T. Iwazaki, W. Sugimoto, and Y. Murakami, Electrochem. Commun., 2, 671 (2000).

19. M. Gustavsson, H. Fredriksson, B. Kasemo, Z. Jusys, J. Kaiser, C. Jun, and R. J. Behm, J. Electroanal. Chem., 568, 371 (2004).

20. A. Foelske-Schmitz, A. Peitz, V. A. Guzenko, D. Weingarth, G. G. Scherer, A. Wokaun, and R. Kötz, Surf. Sci., 606, 1922 (2012).

21. W. Sugimoto, H. Iwata, Y. Yasunaga, Y. Murakami, and Y. Takasu, Angew. Chem., Int. Ed., 42, 4092 (2003).

22. K. Fukuda, H. Kato, J. Sato, W. Sugimoto, and Y. Takasu, J. Solid State Chem., 182, 2997 (2009)

23. J. Sato, H. Kato, M. Kimura, K. Fukuda, and W. Sugimoto, Langmuir, 26, 18049 (2010).

24. P. Shen, N. Chi, K. Y. Chan, and D. L. Phillips, Appl. Surf. Sci., 172, 159 (2001).

25. D. A. J. Rand and R. Woods, J. Electroanal. Chem., 35, 209 (1972).

26. R. Ayala, E. S. Marcos, S. Díaz-Moreno, V. A. Solé, and A. Muñoz-Páez, J. Phys. Chem. B, 105, $7588(2001)$ 